\title{
Reliability Assessment of Transformerless PV Inverters considering Mission Profiles
}

\author{
Yongheng Yang, Huai Wang, and Frede Blaabjerg \\ Department of Energy Technology, Aalborg University, Pontoppidanstraede 101, 9220 Aalborg, Denmark \\ Correspondence should be addressed to Yongheng Yang; yoy@et.aau.dk
}

Received 27 October 2014; Revised 26 January 2015; Accepted 9 February 2015

Academic Editor: Mahmoud M. El-Nahass

Copyright (c) 2015 Yongheng Yang et al. This is an open access article distributed under the Creative Commons Attribution License, which permits unrestricted use, distribution, and reproduction in any medium, provided the original work is properly cited.

\begin{abstract}
Due to the small volume and high efficiency, transformerless inverters have gained much popularity in grid-connected PV applications, where minimizing leakage current injection is mandatory. This can be achieved by either modifying the modulation schemes or adding extra power switching devices, resulting in an uneven distribution of the power losses on the switching devices. Consequently, the device thermal loading is redistributed and thus may alter the entire inverter reliability performance, especially under a long-term operation. In this consideration, this paper assesses the device reliability of three transformerless inverters under a yearly mission profile (i.e., solar irradiance and ambient temperature). The mission profile is translated to device thermal loading, which is used for lifetime prediction. Comparison results reveal the lifetime mismatches among the power switching devices operating under the same condition, which offers new thoughts for a robust design and a reliable operation of grid-connected transformerless PV inverters with high efficiency.
\end{abstract}

\section{Introduction}

Power electronics converter technology has enabled more and more renewable energy installations in recent years, which is also associated with an increasing demand for higher efficiency and higher reliability [1-7]. In order to reduce the cost of energy, the demand will be further strengthened in the future energy mix dominated by wind turbine systems and photovoltaic (PV) systems [8-11]. Transformerless PV inverters have gained much reputation in the European market in terms of high efficiency, small size, and low weight compared to their counterparts [7, 12-16]. Its popularity and its magnificence in conversion efficiency induce a shift in inverter technology in the United States recently [17]. Therefore, an even wide-scale adoption of transformerless PV inverters in the future grid-friendly systems is predictable.

Till now, a vast of transformerless PV inverters have been developed [13-20], and many of those topologies have been successfully commercialized in residential PV applications, where size and efficiency are the main concerns. However, "transformerless" are also required to minimize the leakage current injections for safety due to the removal of the galvanic isolation. This is typically achieved by either developing a special suitable modulation scheme or adding extra power switching devices [18]. For instance, in [19, 20], optimization approaches have been proposed to improve the performance of transformerless PV inverters, while, in [12-14], additional power switching devices have been introduced to the traditional full-bridge PV inverter. However, such software or hardware modifications will alter the power loss distributions on the power switching devices, thus contributing to uneven thermal loading in the PV inverters.

Due to the intermittency of solar energy, transformerless $\mathrm{PV}$ inverters have to handle a fluctuating power. Thus, the thermal loading on each power switching device will be different under a long-term mission profile (e.g., a yearly solar irradiance and ambient temperature profile) [21-24]. The varying thermal loading (appears as fluctuating junction temperature) of the power switching devices is one of the main failure contributors for the power electronics devices [22-29]. As a consequence, the thermal stress difference among the power switching devices will possibly make the entire transformerless PV inverter fail to operate [25-32]. Although more advanced transformerless inverters with a main focus on efficiency are coming on market, there is still a lack of a reliability-oriented investigation considering 


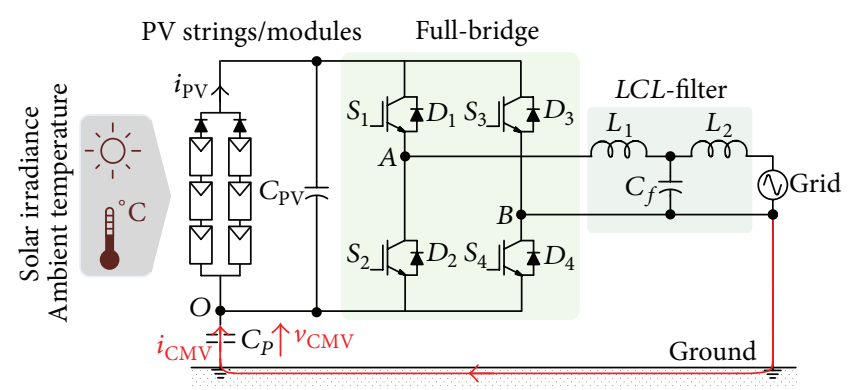

FIGURE 1: A single-phase single-stage grid-connected full-bridge PV inverter system with an $L C L$-filter, where $v_{\mathrm{CMV}}$ is the common mode voltage and $C_{P}$ is the stray capacitor.

mission profiles for those PV inverters. However, such an investigation allows new thoughts for a robust design and a reliable operation of PV system. As a result, a reduction of the cost can be attained since both the efficiency and the reliability of transformerless PV inverters are enhanced.

Taking the above into consideration, this paper explores the thermal performance of three selected transformerless PV inverters under a yearly mission profile, which thus allows a qualitative reliability assessment of the PV inverters beyond efficiency achievements. Firstly, a description of the selected transformerless PV topologies is presented in Section 2. Focus has been put on the mission profile translation to the corresponding device thermal loading of the transformerless inverters in Section 3, where a mission profile based reliability evaluation approach is also introduced. In accordance with the translated thermal loading profiles, Section 4 thus conducts an assessment of the device reliability in those PV inverters before the conclusions.

\section{Selected Transformerless PV Inverters}

Depending on the power ratings, transferring PV energy to an AC power grid has several possibilities $[1,7,33]$. It can be modular PV converters, which typically harvest the energy using DC-DC converters (maximum power point tracking) [34-36], while the string or central inverters can be directly connected to the grid. Since the grid-connected PV systems are still dominantly designed for residential applications [33], the single-phase transformerless PV inverter system is analyzed.

Figure 1 shows the most commonly used single-phase full-bridge (FB) PV inverter topology, where the modulation schemes have to be modified for a smaller leakage current $\left(i_{\mathrm{CMV}}\right)$. As it is shown in Figure 1, an $L C L$-filter is used for a better power quality. In some cases, a DC-DC converter is adopted to boost up the PV output voltage to an acceptable level for the PV inverters. Conventional modulation methods for the single-stage FB inverter topology include the bipolar modulation, the unipolar modulation, and the hybrid modulation. When considering the leakage current injection in transformerless applications, the bipolar modulation scheme is preferable $[12,21]$, which is chosen in this paper. Notably, optimizing the modulation patterns is an alternative to eliminate the leakage currents [19].
As mentioned early, transformerless structures are mostly derived from the FB topology by providing an AC path or a DC path using additional power switching devices. As a result, during the zero-voltage states, isolation between the PV modules and the grid is achieved, thus leading to a low leakage current injection. Figure 2 shows two examples of transformerless PV inverters derived from the single-phase FB topology. As it can be seen in Figure 2(a), the H6 inverter topology [13] has a DC path, which isolates the PV panels from the grid at zero-voltage states. In contrast, although the highly efficient and reliable inverter concept (HERIC) [14] inverter has the same number of power switching devices as that of the $\mathrm{H} 6$ inverter, it provides an AC path to eliminate the leakage current injection.

It should be pointed out that there are also many other transformerless topologies reported in the literature in addition to the above two solutions $[12,16,37]$. For example, the Conergy neutral point clamped (NPC) transformerless $\mathrm{PV}$ inverter is based on the multilevel power converter technology $[12,20]$. However, only the FB inverter with a bipolar modulation scheme (FB-Bipolar), the H6 inverter, and the HERIC inverter are assessed in terms of reliability.

\section{Mission Profile Translation to Thermal Loading}

3.1. Mission Profile for PV Systems. A mission profile is normally referred to a simplified representation of relevant conditions under which the system is operating $[27,32]$. As a result, for the grid-connected PV systems, the mission profile (i.e., solar irradiance and ambient temperature) is actually a reflection of the intermittent nature of the solar PV energy $[38,39]$, and consequently it has an inherent relationship with the entire system performance, including the thermal loading performance. The mission profile can be a series of multitime scales, for example, a minute mission profile or a yearly mission profile, and it is usually taken as the input for the reliability analysis in the field of power electronics converters $[29,39-42]$, which is also focused on in this paper. Figure 3 shows the mission profile applied to the above three transformerless PV inverters.

With more accumulative real-field experience and more advanced real-time monitoring technology, better mission profiles are available for a reasonable lifetime prediction. Hence, a mission profile based analysis approach should be able to analyze the performance at different time scales, as it is shown in Figure 4. It can be observed in Figure 4(a) that, for short-term mission profiles at the level of milliseconds to several seconds, the thermal loading profile can be directly and instantaneously obtained. In contrast, for long-term mission profiles within a range of a few minutes to several months, obtaining the instantaneous thermal loading will be very time-consuming or even impossible when the mission profile has a high data-sampling rate. Alternatively, the thermal loading profile can be obtained based on lookup tables [43], which are created in accordance with the short-term constant mission profiles, as it is shown in Figure 4(b). 


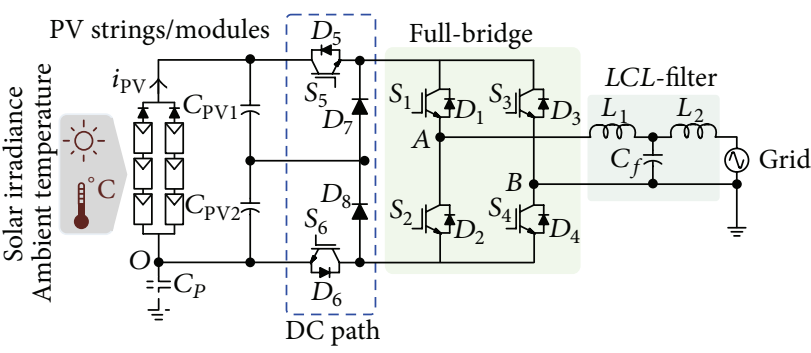

(a)

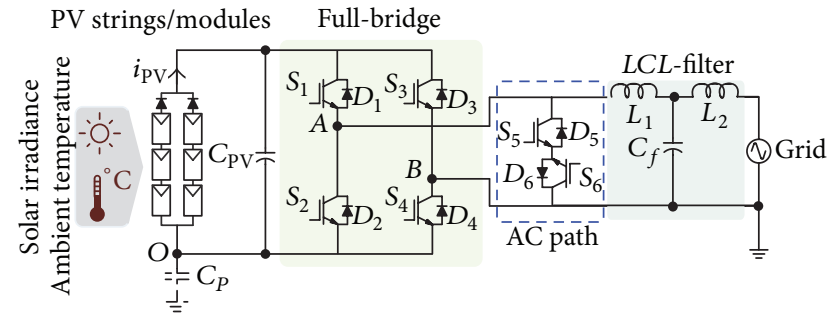

(b)

FIGURE 2: Examples of single-phase transformerless PV inverters derived from the single-phase full-bridge topology by adding extra power switching devices: (a) H6 inverter [13] and (b) HERIC inverter [14].

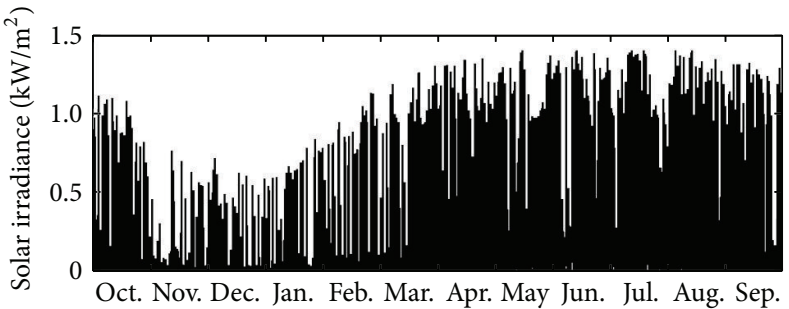

(a)

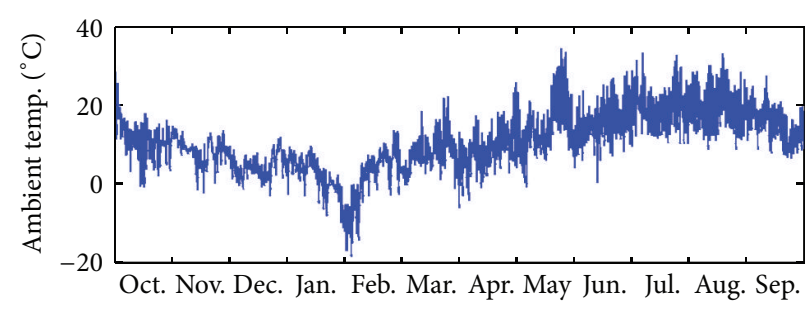

(b)

Figure 3: A yearly mission profile used for the selected transformerless PV inverters (1 sec/sample): (a) solar irradiance and (b) ambient temperature.

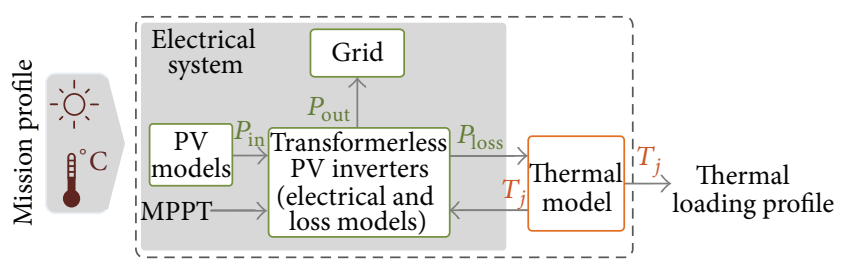

(a)
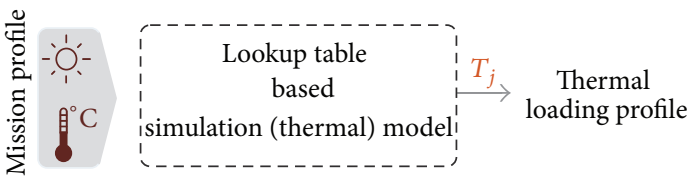

(b)

Figure 4: Approach of the mission profile translation to thermal loading at different time scales (MPPT: maximum power point tracking, $T_{j}$ : junction temperature of the power devices): (a) short-term mission profiles and (b) long-term mission profiles.

3.2. Thermal Modelling of Power Switching Devices. As it is shown in Figure 4, the translation from a mission profile to the corresponding thermal loading profile requires a thermal model which links the electrical performance (power losses, $P_{\text {loss }}$ ) and the thermal behavior (junction temperature, $T_{j}$ ). The coupled relationship is demonstrated in Figure 5 in a FB PV inverter system, which shows that the power losses on the switching devices will introduce a temperature rise due to the thermal impedance in the power switching devices. The thermal impedance can be modeled as a Foster model [43-47], as it is shown in Figure 6. Details of the thermal modelling of power semiconductors can be found in $[46,47]$.

Typically, for such a model of the thermal impedance, the parameter data is provided in the datasheet. Table 1 shows the thermal parameters of the power switching device from a leading manufacturer used in the paper. Notably, all the devices are the same in the three transformerless PV inverters for comparison in terms of thermal loading, and thus the benchmarking results, indicating the critical components of
TABLE 1: Thermal impedance parameters of power switching devices from a leading manufacturer according to Figure 6.

\begin{tabular}{lcccc}
\hline $\begin{array}{l}\text { Impedance } \\
i\end{array}$ & 1 & 2 & 3 & 4 \\
\hline IGBT & & & \\
$\quad R_{\text {th } i}(\mathrm{~K} / \mathrm{W})$ & 0.074 & 0.173 & 0.526 & 0.527 \\
$\quad \tau_{i}(\mathrm{~s})$ & 0.0005 & 0.005 & 0.05 & 0.2 \\
$\begin{array}{l}\text { Diode } \\
\quad R_{\text {th } i}(\mathrm{~K} / \mathrm{W})\end{array}$ & 0.123 & 0.264 & 0.594 & 0.468 \\
$\quad \tau_{i}(\mathrm{~s})$ & 0.0005 & 0.005 & 0.05 & 0.2 \\
\hline
\end{tabular}

transformerless PV inverters, could be a guidance to select appropriate power switching devices in such applications.

3.3. Translated Thermal Loading to Lifetime. Based on the thermal model, simulations have been carried out in PLECS [43] according to Figure 4, where the system parameters are 


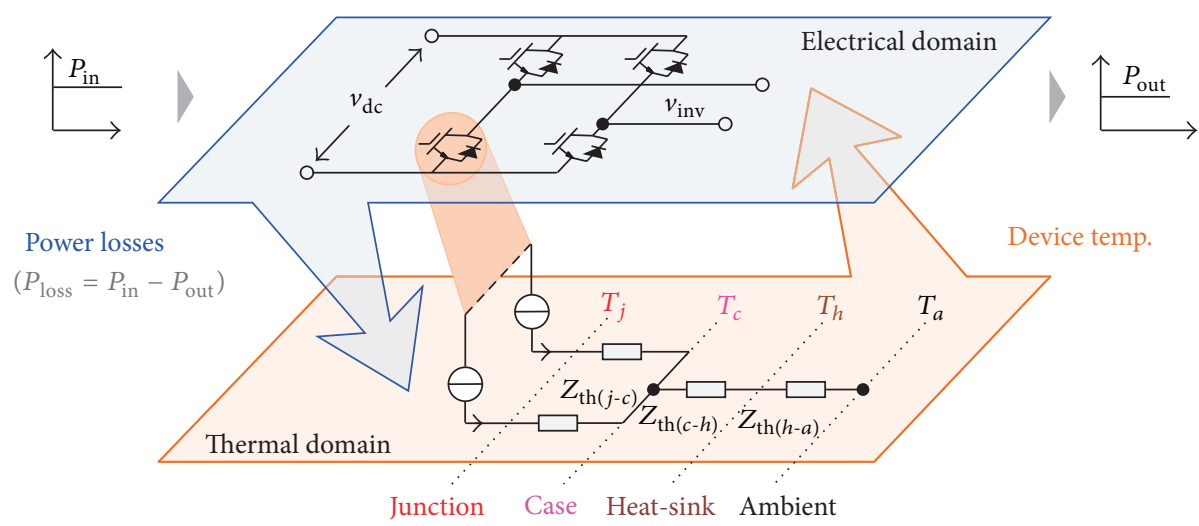

FIGURE 5: Coupled relationship between power losses and the junction temperature of the power switching devices. $Z_{\text {th }(j-c)}$ : junction to case impedance, $Z_{\mathrm{th}(c-h)}$ : case to heat-sink impedance, and $Z_{\mathrm{th}(h-a)}$ : heat-sink to ambient impedance.

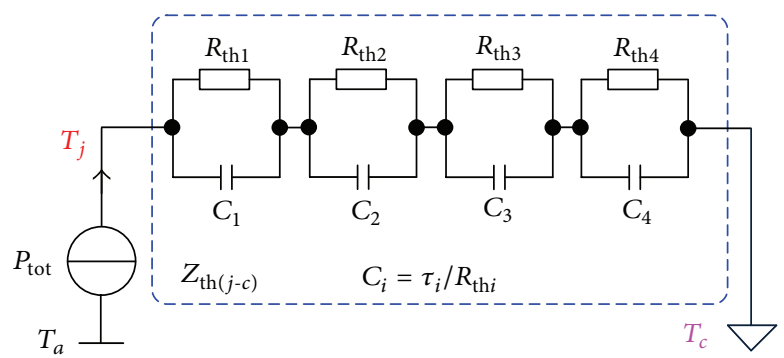

FIGURE 6: Foster model of the junction to case thermal impedance $Z_{\mathrm{th}(j-c)}$ shown in Figure 5.

TABLE 2: System parameters for single-phase transformerless gridconnected PV systems.

\begin{tabular}{lccc}
\hline Parameter & Symbol & Value & Unit \\
\hline Grid voltage & $v_{g, \text { RMS }}$ & 230 & $\mathrm{~V}$ \\
Grid frequency & $f_{g}$ & 50 & $\mathrm{~Hz}$ \\
& $L_{1}$ & 3.6 & $\mathrm{mH}$ \\
LCL-filter & $C_{f}$ & 2.35 & $\mu \mathrm{F}$ \\
& $L_{2}$ & 4 & $\mathrm{mH}$ \\
Damping resistor & $R_{d}$ & 10 & $\Omega$ \\
Switching frequency & $f_{s}$ & 10 & $\mathrm{kHz}$ \\
\hline Parameters of PV strings $(3$ strings, 15 panels for each string $)$ \\
Power at MPP & at $25^{\circ} \mathrm{C}$ and $1 \mathrm{~kW} / \mathrm{m}^{2}$ & & \\
Voltage at MPP & $P_{\mathrm{MPP}}$ & 2.99 & $\mathrm{~kW}$ \\
Current at MPP & $V_{\mathrm{MPP}}$ & 405 & $\mathrm{~V}$ \\
\hline
\end{tabular}

shown in Table 2. In order to create the lookup tables for long-term mission profiles, several constant operating conditions (e.g., solar irradiance: $0.8 \mathrm{~kW} / \mathrm{m}^{2}$, ambient temperature: $25^{\circ} \mathrm{C}$ ) have been simulated firstly, where a perturb-andobserve maximum power point (MPP) tracking algorithm has been used [33-35, 38]. Figure 7 exemplifies the simulation model for a full-bridge inverter system. A proportional resonant current controller has been adopted to control the grid current considering power quality requirements [2]. Using the lookup table model, the yearly mission profile (Figure 3 ) has been resampled ( $5 \mathrm{mins} / \mathrm{sample}$ ) and translated into the thermal loading of the corresponding power switching devices, as it is presented in Figure 8.

Although the transformerless PV inverters (both the H6 and the HERIC) can maintain a higher efficiency as reported in the literature in contrast to the FB-Bipolar inverter, the thermal loading on those switching devices is unequal, as it can be seen in Figure 8. Specifically, the maximum junction temperature of the extra devices in an $\mathrm{H} 6$ inverter is the highest, indicating high power losses, since they are switched at a high frequency. However, this is not the case for the HERIC inverter, where only one of the extra switching devices is switched at the grid frequency during a half cycle. Therefore, the power losses are lower, and thus the thermal loading as it is shown in Figure 8. From the above qualitative analysis, it is implied that much attention has to be paid on the extra switching devices in transformerless PV inverters. Particularly, for the H6 inverter, power switching devices with lower conduction losses and higher rated maximum junction temperature are desirable, while the total cost has to be taken into consideration as well.

When the thermal loading profile appearing in the power switching devices is available, a quantitative prediction of the device lifetime under the mission profile is enabled by a rain-flow counting algorithm $[41,42]$. The rain-flow counting algorithm is a quantitative representation of the thermal loading, which extracts the temperature information in detail in terms of the mean junction temperature $T_{j m}$, temperature 


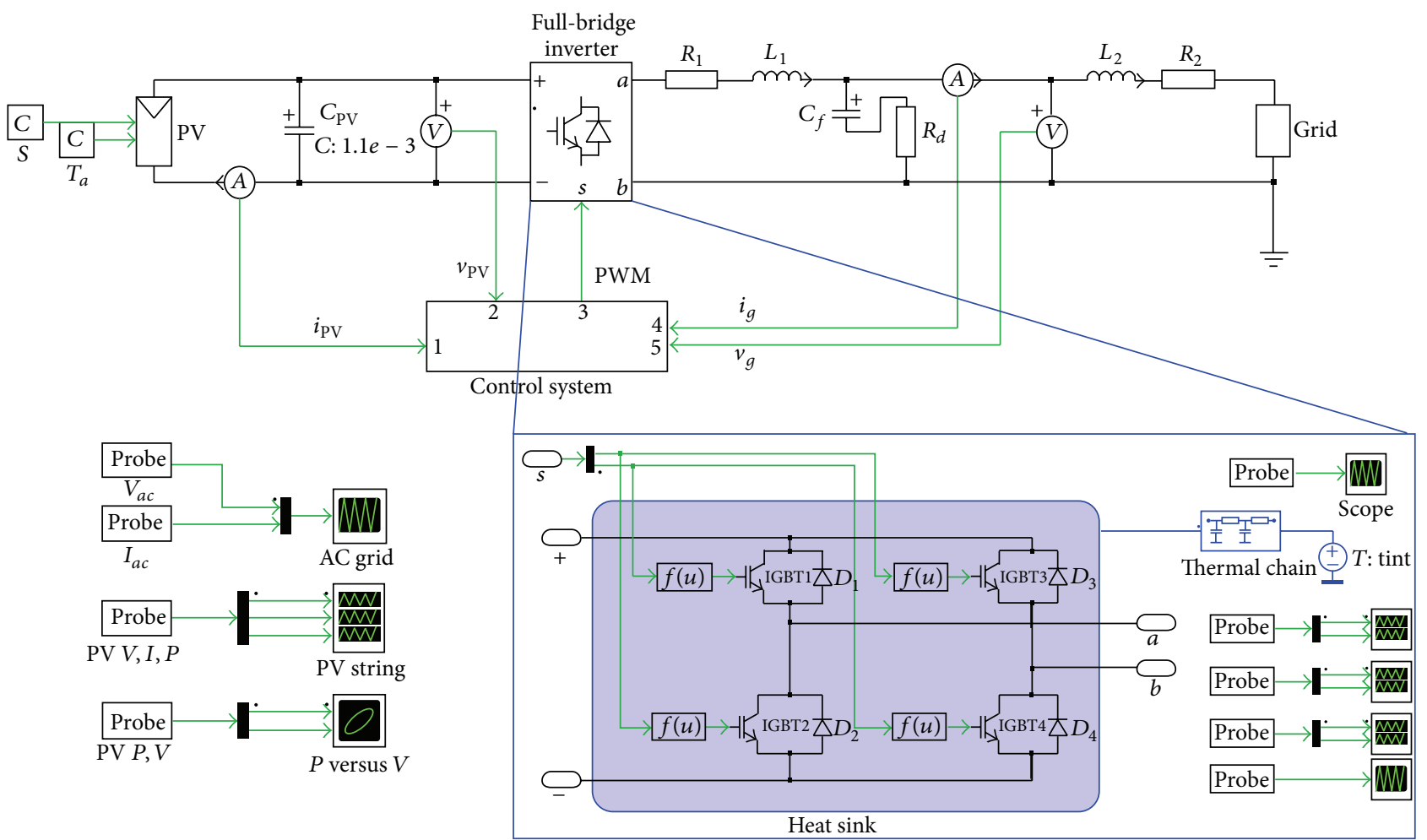

FIGURE 7: Simulation model of a single-phase full-bridge PV inverter system in PLECS.
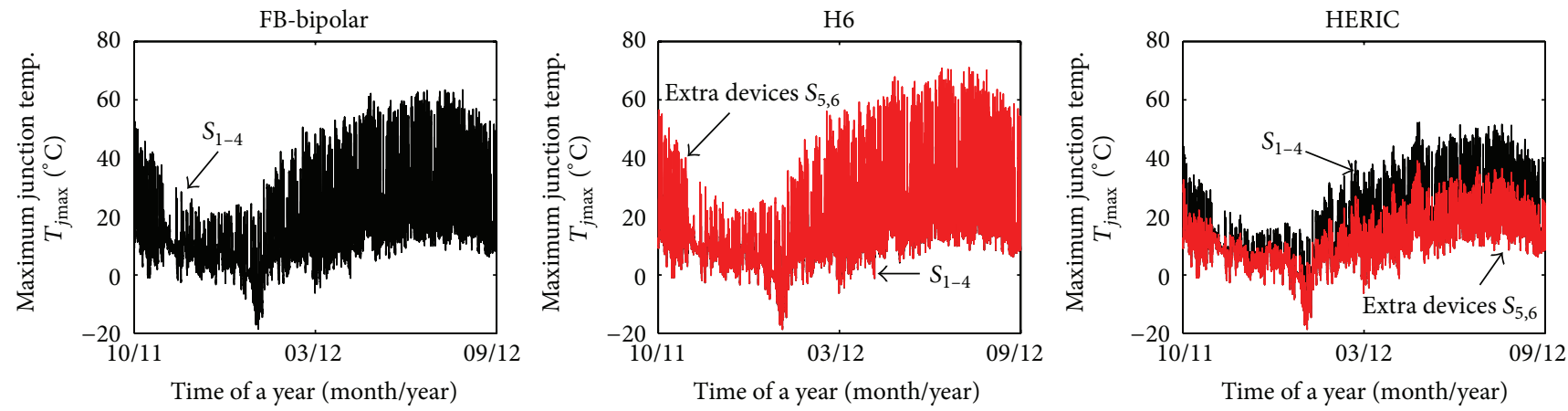

(a)
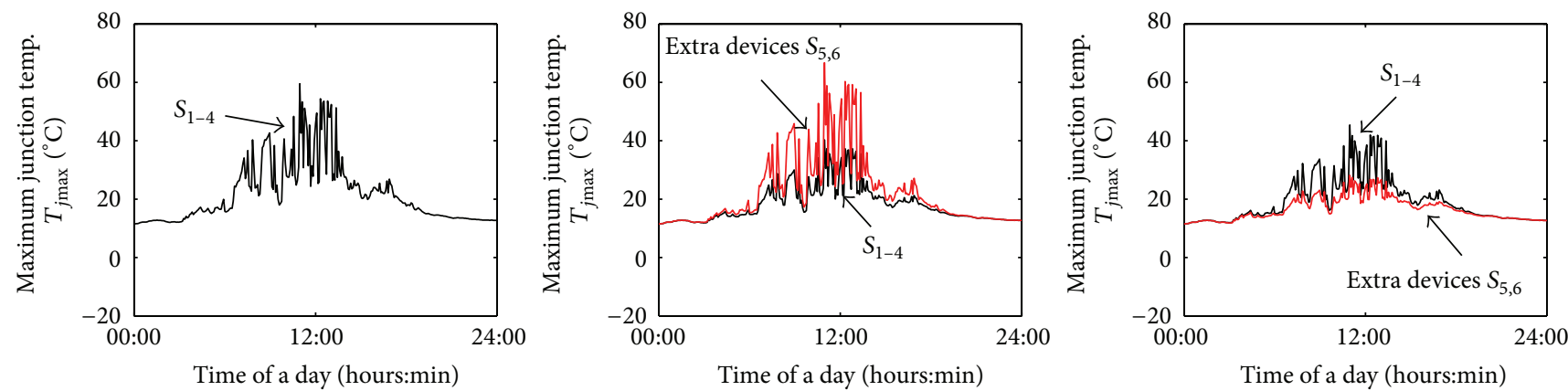

(b)

FIGURE 8: Translated thermal loading (maximum junction temperature, $T_{j \max }$ ) of the power switching devices of the three different transformerless grid-connected PV inverters under a yearly mission profile shown in Figure 3: (a) the yearly long-term thermal loading and (b) details of the maximum junction temperature of the power switching devices in a cloudy day of the year. 
TABLE 3: Parameters of the lifetime model for power devices [48].

\begin{tabular}{lccc}
\hline Parameter & Value & Unit & Experimental condition \\
\hline$A$ & $3.4368 \times 10^{14}$ & - & \\
$\alpha$ & -4.923 & - & $64 \mathrm{~K} \leq \Delta T_{j} \leq 113 \mathrm{~K}$ \\
$\beta_{0}$ & 1.942 & - & $0.19 \leq a r \leq 0.42$ \\
$\beta_{1}$ & $-9.012 \times 10^{-3}$ & - & \\
$C$ & 1.434 & - & $0.07 \mathrm{~s} \leq t_{\text {on }} \leq 63 \mathrm{~s}$ \\
$\gamma$ & -1.208 & - & \\
$f_{d}$ & 0.6204 & - & \\
$E_{a}$ & 0.06606 & $\mathrm{eV}$ & $32.5^{\circ} \mathrm{C} \leq T_{j m} \leq 122^{\circ} \mathrm{C}$ \\
$k_{B}$ & $8.6173324 \times 10^{-5}$ & $\mathrm{eV} / \mathrm{K}$ & \\
\hline
\end{tabular}

cycle amplitude $T_{j}$, cycle period $t_{o n}$, number of cycles $n$, and so forth. Then, the extracted temperature information can be used for the lifetime prediction according to a specific lifetime model. For example, a lifetime model of power switching devices is introduced in [48] and it can be expressed as

$$
N_{f}=A \Delta T_{j}^{\alpha}(a r)^{\beta_{1} \Delta T_{j}+\beta_{0}}\left(\frac{C+\left(t_{o n}\right)^{\gamma}}{C+1}\right) \exp \left(\frac{E_{a}}{k_{B} T_{j m}}\right) f_{d},
$$

where $N_{f}$ is the number of cycles to fail, $f_{d}$ is the diode effect, $a r$ is the bond-wire aspect ratio, $k_{B}$ is the Boltzmann constant, $E_{a}$ is the activation energy, and $A, \alpha, \beta_{0}, \beta_{1}, \gamma$, and $C$ are the lifetime model parameters, as it is shown in Table 3. The lifetime model also implies that the junction temperature has a significant impact on the number of cycles to fail, that is, the reliability of the power switching devices.

According to Miner's rule [24, 42, 48], the life consumption $L C$, the damage due to the thermal stress is the linearly accumulative damage from different thermal cycles. The $L C$ can then be expressed as

$$
L C=\sum_{i} \frac{n_{i}}{N_{f i}}
$$

in which $n_{i}$ is the number of cycles at the stress $\Delta T_{j i}$ extracted by the rain-flow counting algorithm and $N_{f i}$ is the number of cycles to fail based on (1). Subsequently, the lifetime of the power switching devices can be given as

$$
L_{P}=\frac{t_{M P}}{L C}
$$

with $L_{P}$ being the predicted lifetime and $t_{M P}$ being the mission profile period (e.g., a year).

Using the above reliability analysis procedure, the lifetime of the power switching devices in the transformerless PV inverters can then be estimated as long as a mission profile and a lifetime model of high confidence are available. Figure 9 summarizes the mission profile based analysis approach, which can also be used in other power electronics converters, for example, wind turbine converters, where the mission profiles are available.

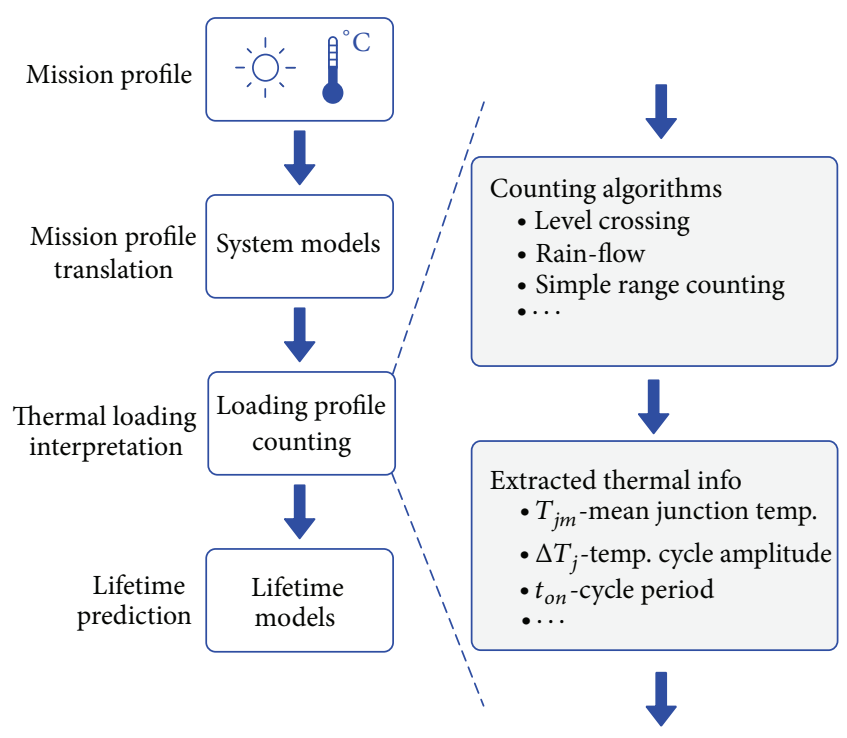

FIGURE 9: Flowchart of the mission profile based reliability analysis approach for transformerless PV inverters.

\section{Reliability Assessment}

According to Figure 9, the lifetime of the power switching devices in the three transformerless PV inverters under the yearly mission profile shown in Figure 3 can be obtained and evaluated. In order to benchmark the reliability quantitatively, the thermal loading profiles have to be interpreted first according to (1) and Figure 9. A rain-flow counting algorithm has been adopted, and the results are presented in Figure 10. It can be observed in Figure 10 that the additional devices of the H6 inverter (i.e., $S_{5}$ and $S_{6}$ ) have a larger number of cycles compared to the other power switching devices of this topology $\left(S_{1 \sim 4}\right)$. This indicates that the extra devices to realize an elimination of the leakage currents become the most critical components of the H6 inverter according to (2) and (3). As a consequence, more reliable power devices are preferable as the extra devices when designing an H6 based transformerless PV system. In the case of the HERIC inverter based transformerless PV systems, the extra devices have a smaller number of cycles compared to those of the H6 inverter. Moreover, the number of cycles of the other power switching devices of the HERC inverter is even smaller than that of the FB-Bipolar inverter under the same mission profile. This means that the thermal stress on the power switching devices of the HERIC inverter is the lowest, and thus the HERIC inverter can achieve the highest reliability if the same mission profile is applied to those inverter candidates, while also maintaining a higher efficiency as it is reported in $[12,14]$. The discussion is in agreement with the analysis presented in Section 3.3 based on the translated thermal loading profiles.

It should be noted that the life consumption and thus the lifetime of the power switching devices according to (2) and (3) can quantitatively be obtained on condition that the lifetime model of (1) and also the parameters given in Table 3 are at a high confident level. However, those parameters are 

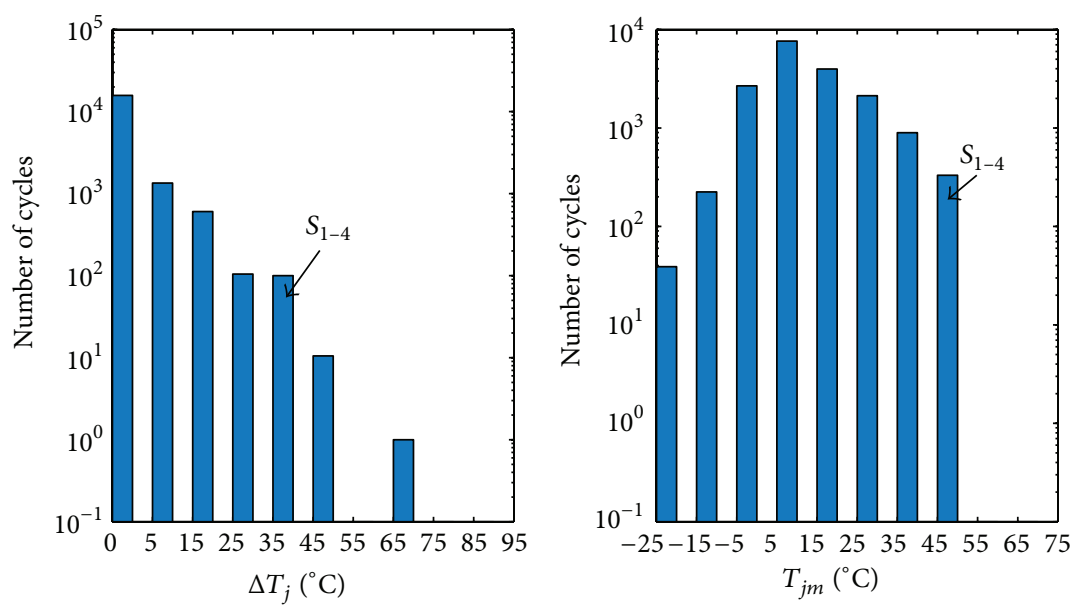

(a)
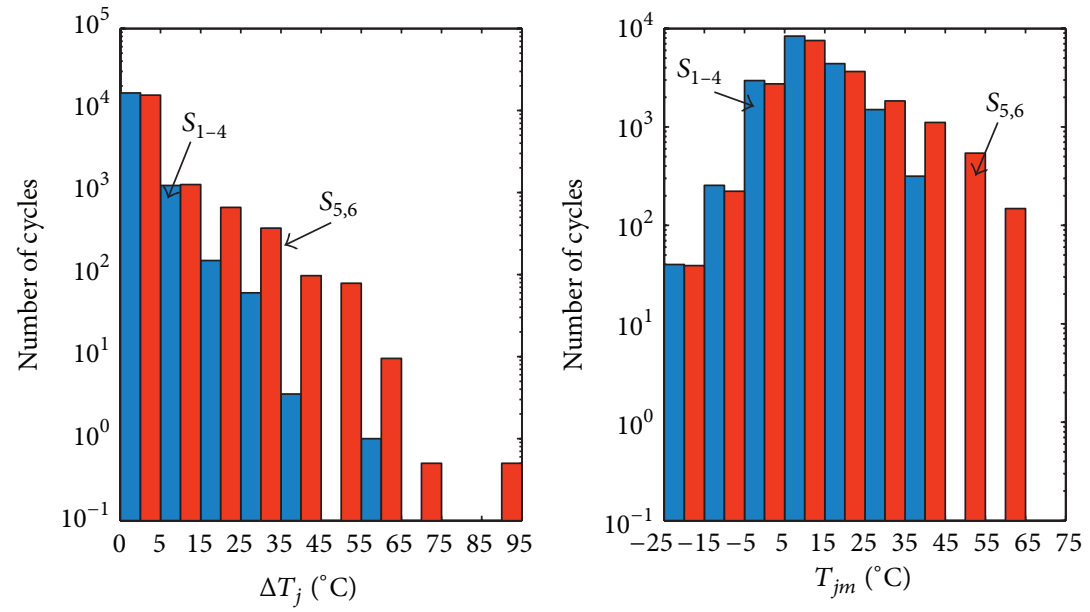

(b)
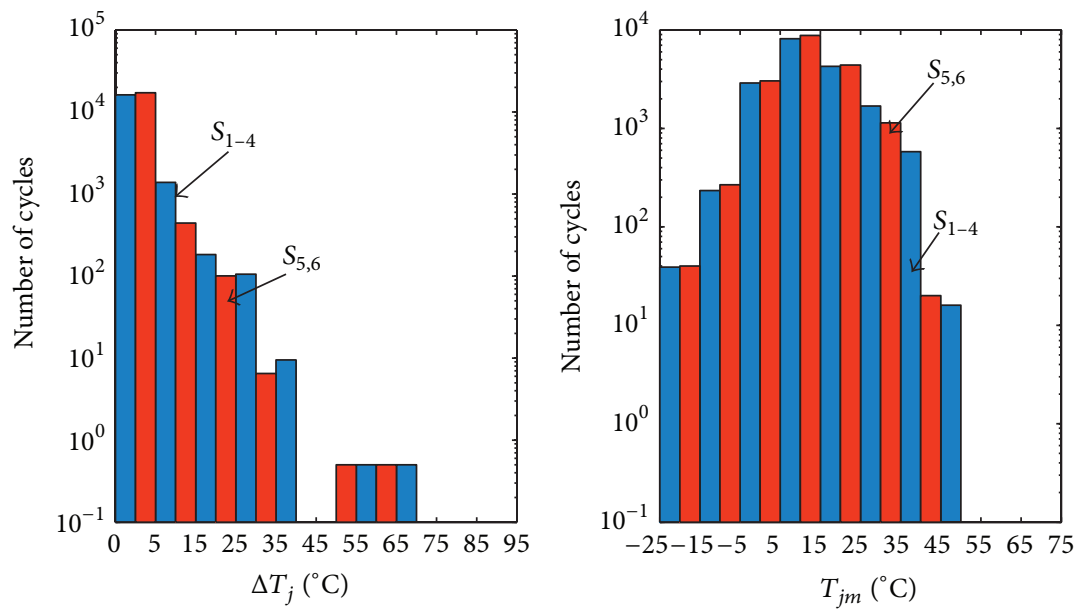

(c)

FIgURE 10: Rain-flowing counting results (number of cycles distributions at the cycle amplitude $\Delta T_{j}$ and the mean junction temperature $T_{j m}$ ) of the thermal loading profiles shown in Figure 8: (a) FB-Bipolar inverter, (b) H6 inverter, and (c) HERIC inverter. 


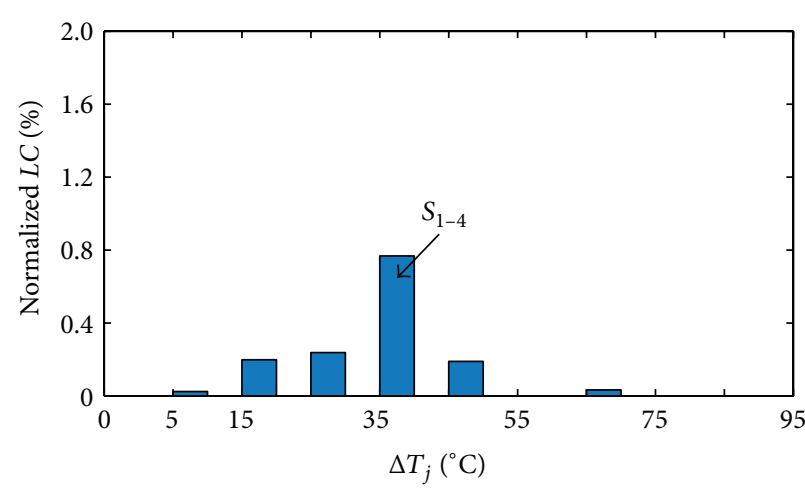

(a)

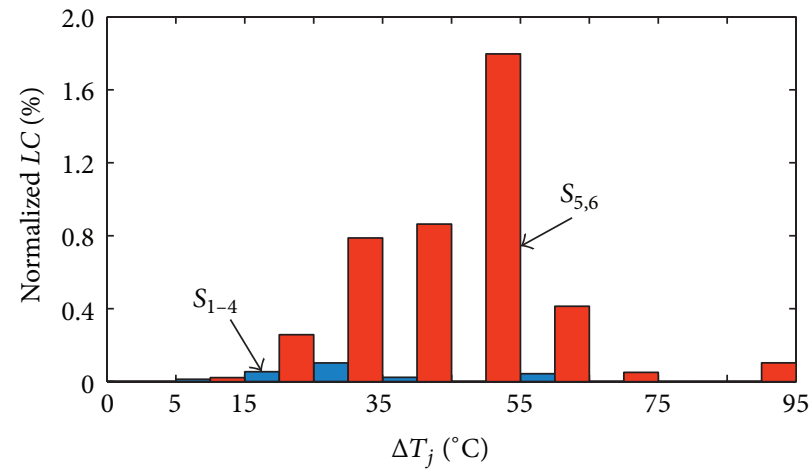

(b)

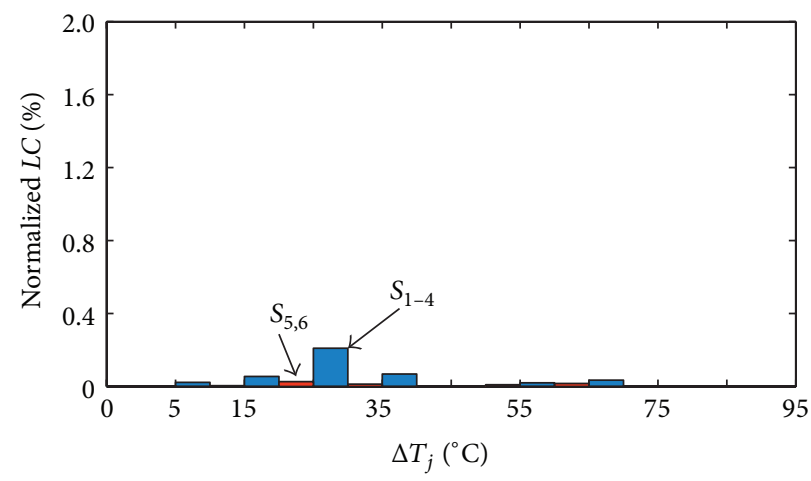

(c)

FIgURE 11: Normalized life consumption (lifetime comparison) of the three transformerless PV inverters under the same mission profile: (a) FB-Bipolar inverter, (b) H6 inverter, and (c) HERIC inverter.

extracted under specific conditions (e.g., $0.07 \mathrm{~s} \leq t_{\text {on }} \leq$ $63 \mathrm{~s}$ ) for the power switching devices introduced in [48]. Therefore, quantitative prediction errors will be inevitable. In order to reduce the parameter dependency and also the reliability model dependency, the life consumption given in (2) is normalized, and substituting (1) yields

$$
\begin{aligned}
& \overline{L C}=\frac{L C}{L C_{b}} \\
& =\left(\sum_{i} \frac{n_{i}}{\left(\Delta T_{j i}\right)^{\alpha}(a r)^{\beta_{1} \Delta T_{j i}}\left[C+\left(t_{\text {oni }}\right)^{\gamma}\right] e^{E_{a} /\left(k_{B} T_{j m i}\right)}}\right)
\end{aligned}
$$

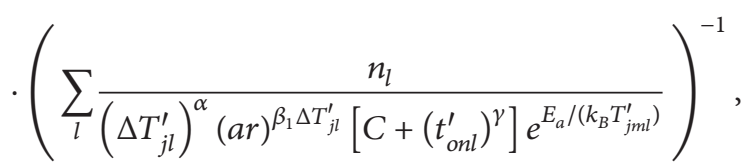

where $\overline{L C}$ is the normalized life consumption and $L C_{b}$ is the base $L C$ for normalization. For example, $L C_{b}$ can be chosen as the life consumption of the power switching devices of the FB-Bipolar inverter under the same mission profile. Then, the predicted lifetime can be expressed as

$$
L_{p}=\frac{1}{\overline{L C}} L_{p}^{\prime}
$$

in which $L_{p}^{\prime}$ is the predicted lifetime of the base system used for normalization.

Figure 11 shows the normalized life consumption of the three transformerless PV inverters according to (4) and the counting results enabled by a rain-flow algorithm. The life consumption of the power switching devices of the FBBipolar (i.e., $S_{1 \sim 4}$ ) is selected as the base life consumption for normalization in Figure 11. It can be seen in Figure 11 that the extra power switching devices of the H6 inverter consume much more life compared to the other devices and also those of the HERIC inverter. It implies that the degradation of the additional devices of the H6 inverter happens much faster, and then the entire $\mathrm{H} 6$ system may fail to operate earlier than the other two transformerless PV inverters. This comparison further confirms that the HERIC inverter would be the most promising solution in terms of reliability.

In addition, by comparing the rain-flow counting results shown in Figure 10 with the normalized life consumption shown in Figure 11, one interesting conclusion can be drawn which is that although there are a few cycles of a large temperature cycling amplitude (e.g., ten cycles of $55^{\circ} \mathrm{C}$ to $65^{\circ} \mathrm{C}$ for the extra devices $S_{5,6}$ of the H6 inverter), they do contribute much more damage (e.g., $0.4 \%$ in Figure $11(\mathrm{~b})$ ) when the lifetime model of (1) is adopted. Large cycling amplitude is mainly induced by the mission profile, which confirms that the mission profile effect has to be taken into account in a reliability-oriented design of power electronics 
converters. In a word, the reliability assessment in this paper reveals that much attention has to be put on the thermal design of the critical components in an entire PV inverter in order to reduce the cost of energy.

\section{Conclusions}

In this paper, a qualitative reliability assessment of three selected single-phase transformerless PV inverters has been carried out in accordance with a mission profile based reliability analysis approach. A real-field yearly mission profile has been applied to the selected transformerless candidates for the reliability assessment. The comparison results have revealed that although minimizing leakage currents as well as maintaining a satisfactory efficiency has been targeted by those inverters, the extra devices that are used for disconnection of the PV panels or the PV inverters might be heated up during operation. The high thermal loading will further induce failures of the power switching devices, being a big challenge to the entire system reliability. As a consequence, many efforts should be devoted to a reliabilityoriented design of the critical components in a PV inverter, and thus a reduced cost of energy can be achieved.

\section{Conflict of Interests}

The authors declare that there is no conflict of interests regarding the publication of this paper.

\section{References}

[1] F. Blaabjerg, K. Ma, and Y. Yang, "Power electronics-the key technology for renewable energy systems," in Proceedings of the 9th International Conference on Ecological Vehicles and Renewable Energies (EVER '14), pp. 1-11, Monte-Carlo, Monaco, March 2014.

[2] F. Blaabjerg, R. Teodorescu, M. Liserre, and A. V. Timbus, "Overview of control and grid synchronization for distributed power generation systems," IEEE Transactions on Industrial Electronics, vol. 53, no. 5, pp. 1398-1409, 2006.

[3] J. M. Carrasco, L. G. Franquelo, J. T. Bialasiewicz et al., "Powerelectronic systems for the grid integration of renewable energy sources: a survey," IEEE Transactions on Industrial Electronics, vol. 53, no. 4, pp. 1002-1016, 2006.

[4] J. D. van Wyk and F. C. Lee, "On a future for power electronics," IEEE Journal of Emerging and Selected Topics in Power Electronics, vol. 1, no. 2, pp. 59-72, 2013.

[5] A. Golnas, "PV system reliability: an operator's perspective," IEEE Journal of Photovoltaics, vol. 3, no. 1, pp. 416-421, 2013.

[6] A. Ristow, M. Begović, A. Pregelj, and A. Rohatgi, "Development of a methodology for improving photovoltaic inverter reliability," IEEE Transactions on Industrial Electronics, vol. 55, no. 7, pp. 2581-2592, 2008.

[7] E. Romero-Cadaval, G. Spagnuolo, L. G. Franquelo, C. A. Ramos-Paja, T. Suntio, and W. M. Xiao, "Grid-connected photovoltaic generation plants: components and operation," IEEE Industrial Electronics Magazine, vol. 7, no. 3, pp. 6-20, 2013.

[8] REN21, "Renewables 2014 global status report," Tech. Rep., 2014, http://www.ren21.net/.

[9] M. Liserre, T. Sauter, and J. Y. Hung, "Future energy systems: integrating renewable energy sources into the smart power grid through industrial electronics," IEEE Industrial Electronics Magazine, vol. 4, no. 1, pp. 18-37, 2010.

[10] C.-L. Shen and S.-H. Yang, "Multi-input converter with MPPT feature for wind-PV power generation system," International Journal of Photoenergy, vol. 2013, Article ID 129254, 13 pages, 2013.

[11] F. Blaabjerg and K. Ma, "Future on power electronics for wind turbine systems," IEEE Journal of Emerging and Selected Topics in Power Electronics, vol. 1, no. 3, pp. 139-152, 2013.

[12] R. Teodorescu, M. Liserre, and P. Rodriguez, Grid Converters for Photovoltaic and Wind Power Systems, Wiley-IEEE Press, 2011.

[13] R. González, J. López, P. Sanchis, and L. Marroyo, "Transformerless inverter for single-phase photovoltaic systems," IEEE Transactions on Power Electronics, vol. 22, no. 2, pp. 693-697, 2007.

[14] H. Schmidt, C. Siedle, and J. Ketterer, "DC/AC converter to convert direct electric voltage into alternating voltage or into alternating current," U.S. Patent 7046534, 2006.

[15] T. Kerekes, M. Liserre, R. Teodorescu, C. Klumpner, and M. Sumner, "Evaluation of three-phase transformerless photovoltaic inverter topologies," IEEE Transactions on Power Electronics, vol. 24, no. 9, pp. 2202-2211, 2009.

[16] R. González, E. Gubía, J. López, and L. Marroyo, “Transformerless single-phase multilevel-based photovoltaic inverter," IEEE Transactions on Industrial Electronics, vol. 55, no. 7, pp. 26942702,2008

[17] Advanced Energy, "What's ahead for PV inverter technology?" Greentechsolar, 2014, http://www.greentechmedia.com/.

[18] I. Patrao, E. Figueres, F. González-Espín, and G. Garcerá, "Transformerless topologies for grid-connected single-phase photovoltaic inverters," Renewable and Sustainable Energy Reviews, vol. 15, no. 7, pp. 3423-3431, 2011.

[19] N. Achilladelis, E. Koutroulis, and F. Blaabjerg, "Optimized pulse width modulation for transformerless active-NPC inverters," in Proceedings of the 16th European Conference on Power Electronics and Applications (EPE '14-ECCE Europe), pp. 1-10, Lappeenranta, Finland, August 2014.

[20] S. Saridakis, E. Koutroulis, and F. Blaabjerg, "Optimal design of modern transformerless PV inverter topologiesd," IEEE Transactions on Energy Conversion, vol. 28, no. 2, pp. 394-404, 2013.

[21] Y. Yang, H. Wang, F. Blaabjerg, and K. Ma, "Mission profile based multi-disciplinary analysis of power modules in singlephase transformerless photovoltaic inverters," in Proceedings of the 15th European Conference on Power Electronics and Applications (EPE '13), pp. 1-10, IEEE, Lille, France, September 2013.

[22] S. E. de Léon-Aldaco, H. Calleja, F. Chan, and H. R. JiménezGrajales, "Effect of the mission profile on the reliability of a power converter aimed at photovoltaic applications-a case study," IEEE Transactions on Power Electronics, vol. 28, no. 6, pp. 2998-3007, 2013.

[23] H. Wang, M. Liserre, and F. Blaabjerg, "Toward reliable power electronics: challenges, design tools, and opportunities," IEEE Industrial Electronics Magazine, vol. 7, no. 2, pp. 17-26, 2013.

[24] H. Huang and P. A. Mawby, "A lifetime estimation technique for voltage source inverters," IEEE Transactions on Power Electronics, vol. 28, no. 8, pp. 4113-4119, 2013.

[25] P. McCluskey, "Reliability of power electronics under thermal loading," in Proceedings of the 7th International Conference on Integrated Power Electronics Systems (CIPS '12), March 2012. 
[26] H. Lu, C. Bailey, and C. Yin, "Design for reliability of power electronics modules," Microelectronics Reliability, vol. 49, no. 911, pp. 1250-1255, 2009.

[27] M. Ciappa, "Lifetime prediction on the base of mission profiles," Microelectronics Reliability, vol. 45, no. 9-11, pp. 1293-1298, 2005.

[28] F. Chan and H. Calleja, "Reliability estimation of three singlephase topologies in grid-connected PV systems," IEEE Transactions on Industrial Electronics, vol. 58, no. 7, pp. 2683-2689, 2011.

[29] K. Ma, M. Liserre, F. Blaabjerg, and T. Kerekes, “Thermal loading and lifetime estimation for power device considering mission profiles in wind power converter," IEEE Transactions on Power Electronics, vol. 30, no. 2, pp. 590-602, 2015.

[30] S. Harb and R. S. Balog, "Reliability of candidate photovoltaic module-integrated-inverter (PV-MII) topologies-a usage model approach," IEEE Transactions on Power Electronics, vol. 28, no. 6, pp. 3019-3027, 2013.

[31] P. Zhang, Y. Wang, W. Xiao, and W. Li, "Reliability evaluation of grid-connected photovoltaic power systems," IEEE Transactions on Sustainable Energy, vol. 3, no. 3, pp. 379-389, 2012.

[32] S. E. De León-Aldaco, H. Calleja, and J. Aguayo, "Reliability and mission profiles of photovoltaic systems: a FIDES approach," IEEE Transactions on Power Electronics, vol. 30, no. 5, pp. 25782586, 2015.

[33] S. B. Kjaer, J. K. Pedersen, and F. Blaabjerg, "A review of singlephase grid-connected inverters for photovoltaic modules," IEEE Transactions on Industry Applications, vol. 41, no. 5, pp. 12921306, 2005.

[34] H. Li, J. Peng, W. Liu, Z. Huang, and K.-C. Lin, "A newton-based extremum seeking MPPT method for photovoltaic systems with stochastic perturbations," International Journal of Photoenergy, vol. 2014, Article ID 938526, 13 pages, 2014.

[35] D. Sera, L. Mathe, T. Kerekes, S. V. Spataru, and R. Teodorescu, "On the perturb-and-observe and incremental conductance mppt methods for PV systems," IEEE Journal of Photovoltaics, vol. 3, no. 3, pp. 1070-1078, 2013.

[36] M. Abdulkadir, A. H. M. Yatim, and S. T. Yusuf, "An improved PSO-based MPPT control strategy for photovoltaic systems," International Journal of Photoenergy, vol. 2014, Article ID 818232, 11 pages, 2014.

[37] Y. Zhou and H. Li, "Analysis and suppression of leakage current in cascaded-multilevel-inverter-based PV systems," IEEE Transactions on Power Electronics, vol. 29, no. 10, pp. 5265-5277, 2014.

[38] A. Hajiah, T. Khatib, K. Sopian, and M. Sebzali, "Performance of grid-connected photovoltaic system in two sites in Kuwait," International Journal of Photoenergy, vol. 2012, Article ID 178175, 7 pages, 2012.

[39] M. Musallam, C. Yin, C. Bailey, and M. Johnson, "Mission profile-based reliability design and real-time life consumption estimation in power electronics," IEEE Transactions on Power Electronics, vol. 30, no. 5, pp. 2601-2613, 2015.

[40] Y. Yang, H. Wang, F. Blaabjerg, and T. Kerekes, "A hybrid power control concept for PV inverters with reduced thermal loading," IEEE Transactions on Power Electronics, vol. 29, no. 12, pp. 62716275, 2014.

[41] A. T. Bryant, P. A. Mawby, P. R. Palmer, E. Santi, and J. L. Hudgins, "Exploration of power device reliability using compact device models and fast electrothermal simulation," IEEE Transactions on Industry Applications, vol. 44, no. 3, pp. 894903, 2008.
[42] M. Musallam and C. M. Johnson, "An efficient implementation of the rainflow counting algorithm for life consumption estimation," IEEE Transactions on Reliability, vol. 61, no. 4, pp. 978986, 2012.

[43] Plexim Gmbh, "PLECS—the simulation platform for power electronics systems," Workshop Documentation 1, Aalborg, 2014.

[44] I. F. Kovačević, U. Drofenik, and J. W. Kolar, "New physical model for lifetime estimation of power modules," in Proceedings of the International Power Electronics Conference (IPEC '10), pp. 2106-2114, Sapporo, Japan, June 2010.

[45] C. Busca, R. Teodorescu, F. Blaabjerg et al., "An overview of the reliability prediction related aspects of high power IGBTs in wind power applications," Microelectronics Reliability, vol. 51, no. 9-11, pp. 1903-1907, 2011.

[46] ABB, "Application Note-Applying IGBTs," 2014, http://www .abb.com/.

[47] A. Volke and M. Hornkamp, IGBT Modules-Technologies, Driver and Application, Infineon Technologies AG, Munich, Germany, 2012.

[48] U. Scheuermann, "Reliability of advanced power modules for extended maximum junction temperatures," Bodo's Power Systems, pp. 26-30, 2014. 

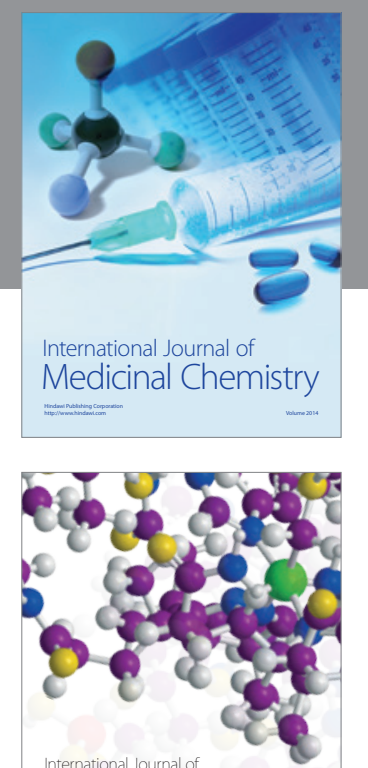

\section{Carbohydrate} Chemistry

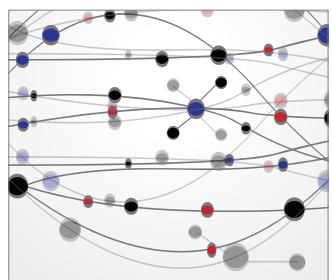

The Scientific World Journal
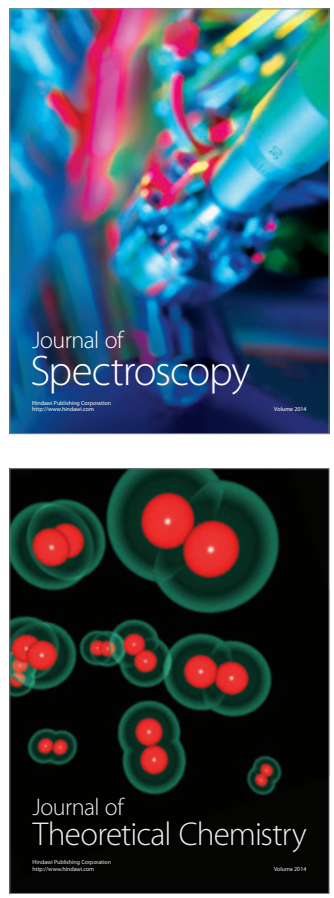
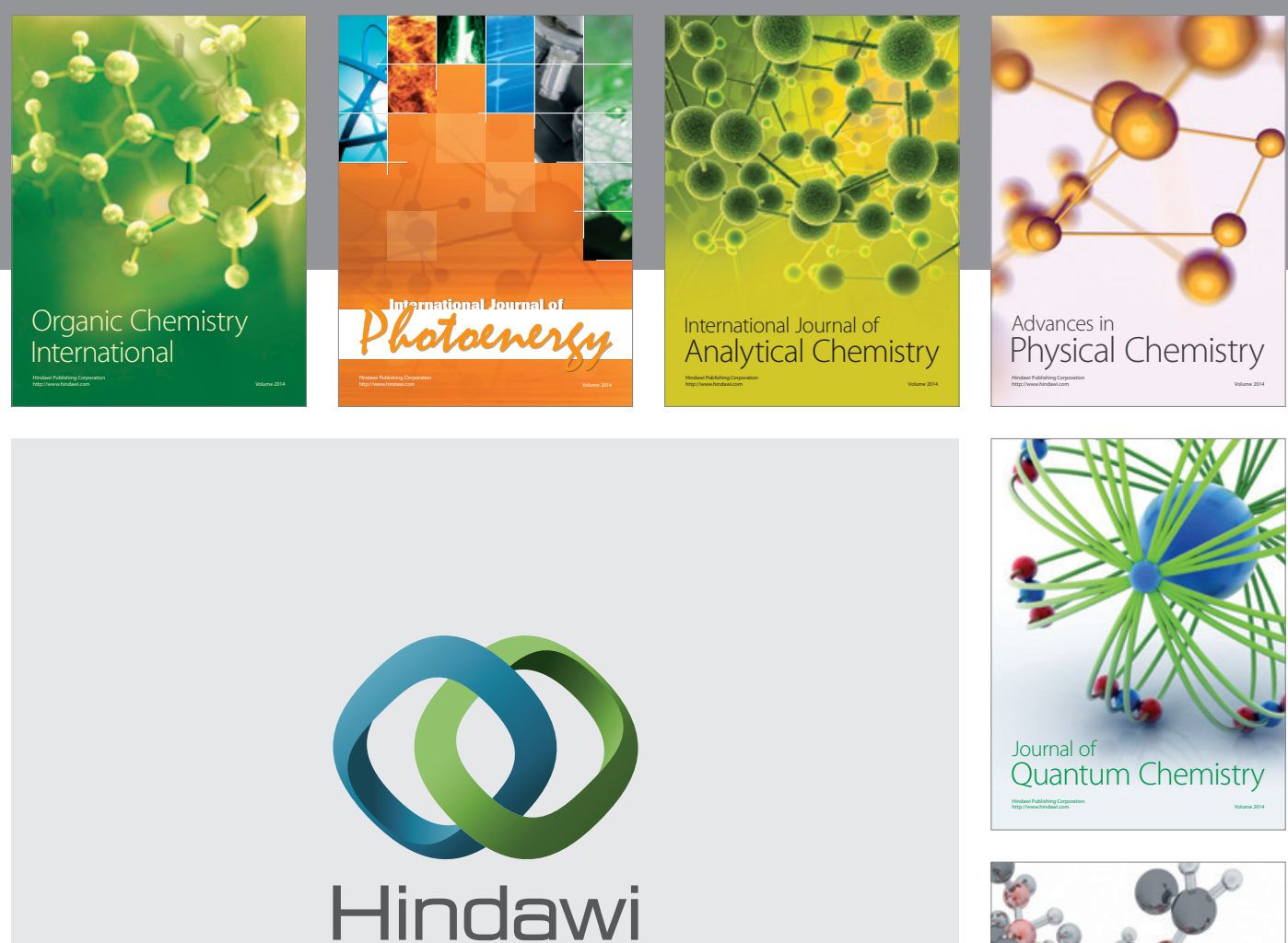

Submit your manuscripts at

http://www.hindawi.com

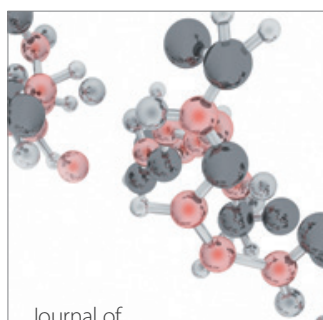

Analytical Methods

in Chemistry

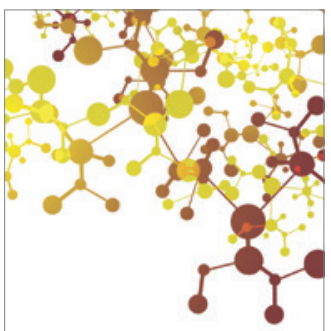

Journal of

Applied Chemistry

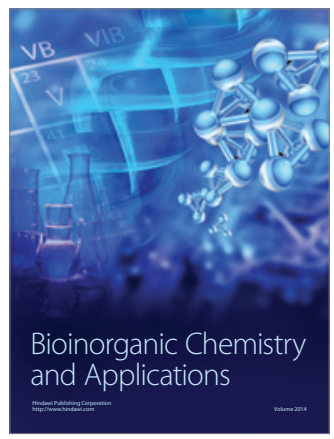

Inorganic Chemistry
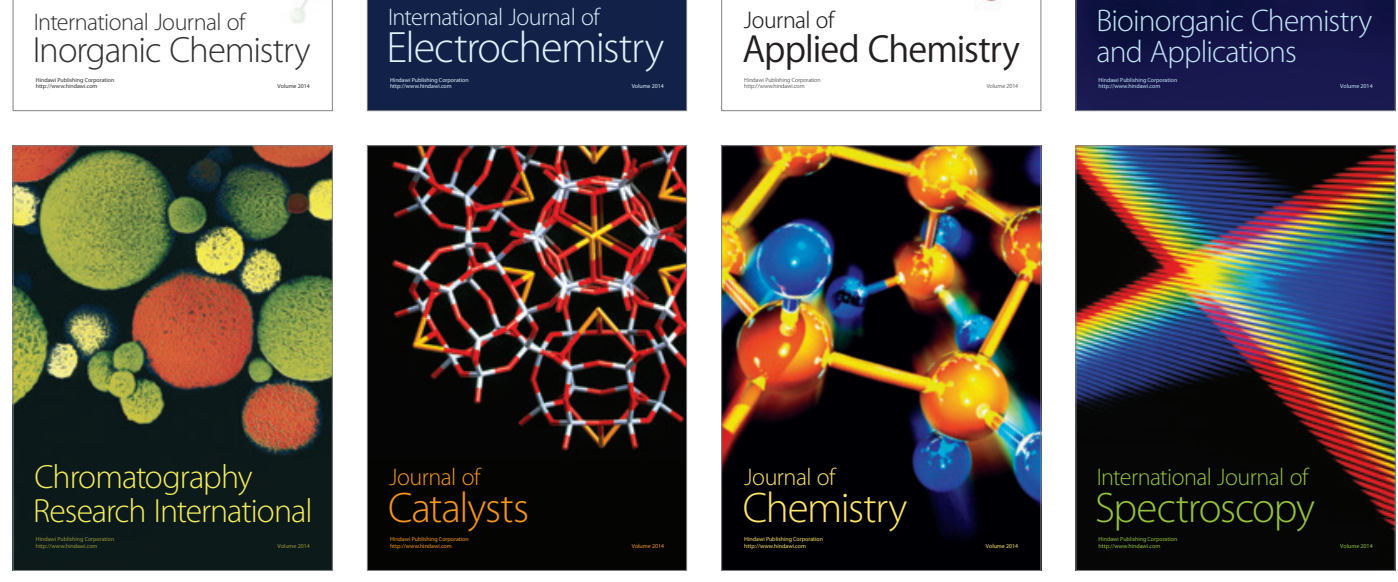